\title{
One Step Shoulder Soft Tissues Reconstruction and Surgery Treatment of Triangle Tilt of Glenoid Due to Sequlae of Brachial Plexus Birth Palsy
}

\author{
Mohamed Abdelaziz MA Ghieth ${ }^{1 *}$, Sayed El-Etewy Saoudy ${ }^{2}$ \\ ${ }^{1}$ Lecturer of Orthopedic Surgery, Faculty of Medicine, Zagazig University, Egypt \\ ${ }^{2}$ Assistant Professor of Orthopedic Surgery, Zagazig University, Egypt
}

"Corresponding Author: Mohamed Abdelaziz MA Ghieth, Lecturer of Orthopedic Surgery, Faculty of Medicine, Zagazig University, Egypt, E-mail: yousufmmkh@gmail.com

\begin{abstract}
Objective: Brachial Plexus Birth palsy usually result in Shoulder deformities lead to poor function, loss of quality of life and pain. The purpose of our study is to examine the results of combined in one step shoulder soft tissues reconstruction and triangle tilt procedure on improvement of shoulder function and development.
\end{abstract}

Method: A major treatment goal in children with obstetric brachial plexus palsy $(O B P P)$ is to obtain optimal range of shoulder motion through improved glenohumeral alignment. In our study (34 cases of shoulder sequelae in brachial plexus birth palsy) medial rotation contracture with shoulder subluxation or dislocation and SHEAR deformity, mean age (5.4 year), mean follow up (31.2 months). We combine in one step anterior shoulder release (subscapularis release, coracohumeral and coracoacromial ligament release, pectoralis major lengthening, latissimusdorsi and teres major transfer to teres minor and the triangle tilt procedure, establishing glenohumeral congruency is the target, repositioning of the glenohumeral joint to maximize alignment does not only improve function and growth, but has been provided encourage joint remodeling

Results: 34 cases of ( OBPP ) with medial rotation contracture with shoulder subluxation or dislocation and SHEAR deformity, mean age ( 5.4 year ), mean follow up ( 31.2 months ) combined in one step shoulder soft tissues reconstruction and triangle tilt resulted in significant increase in overall modified Mallet score ( 11.2) to ( 19.7$), p$ value $(<0.0001)$ and significant increase in mean glenoid version ( 17.2$)$ to $(-4), p$ value ( $<0.0001)$, mean percentage of humeral head anterior ( 8 ) to ( 47.8$)$, p value ( $<0.0001$ ) and mean scapular elevation ( 20.7 ) to ( 7.4 ), p value (<0.0001), difference in abduction and scapular elevation were significantly correlated with age, for the difference in abduction $(r=-0.4, p=0.0029)$ and for the difference in scapular elevation $(r=-0.4, p=0.0045)$.

Conclusion: statistically significant improvement in shoulder function and radiological outcomes after our study (combined in one step shoulder soft tissues reconstruction and Triangle tilt) is good method for patients who have developed a medial rotation contracture with shoulder subluxation or dislocation and SHEAR deformity. Anterior shoulder release addresses the contracted Anterior structure of shoulder joint so relocate the humeral head in anterior glenoid fossa, the triangle tilt procedure addresses medial rotation and glenohumeral deformity, so in our study we can manage late sequlae of shoulder in OBBP.

Keywords: Shoulder, Tilt, Osteotomy, Brachial, Obstetrics

List of Abbreviations: OBPP: Obstetric brachial plexus palsy,

SHAER: Scapular hypoplasia, elevation, and rotation deformity,

$M R C$ : Medial rotation contracture,

ACT: Acromial clavicular triangle,

TT: Triangle tilt,

AROM: Active range of motion),

PHHA: Percentage of humeral head anterior,

Deg: Degree. 


\section{INTRODUCTION}

The prevalence of shoulder contracture and osseous deformity in birth palsy is high. [1]. Normal shoulder function is dependent on osteocartilaginous elements, joint capsule, muscles, and central nervous system factors [2]. Muscular imbalance, Cross-innervation, and Growth are the three main causes of shoulder deformity due to birth palsy [3]. The muscular imbalance results in joint malpositioning that will produce osseous deformities of the shoulder which are aggravated by growth [4]. The Heuter-Volkmann law confirmed that the growth plate is responsive to an applied load. After residual brachial plexus birth palsy, the constant position of medial rotation prevents a balanced range of motion and focuses the glenohumeral load over a limited surface area. This stress along the posterior glenoid hinder normal glenohumeral maturation, increase progressive glenohumeral dysplasia, and promotes humeral head subluxation [5]. The severe trauma that results in significant brachial plexus avulsions and epiphysiolysis of the humeral head would result in a lesion in the periarticular muscles of the shoulder. Muscles contractures may occur with growth in patients with internal rotation contractures of the shoulder [6]. Medial rotation contracture applies posteriorly displacing forces on the humeral head, so the normal glenoid is deformed either by erosion or inhibited development [7] (Fig. 1) [8].

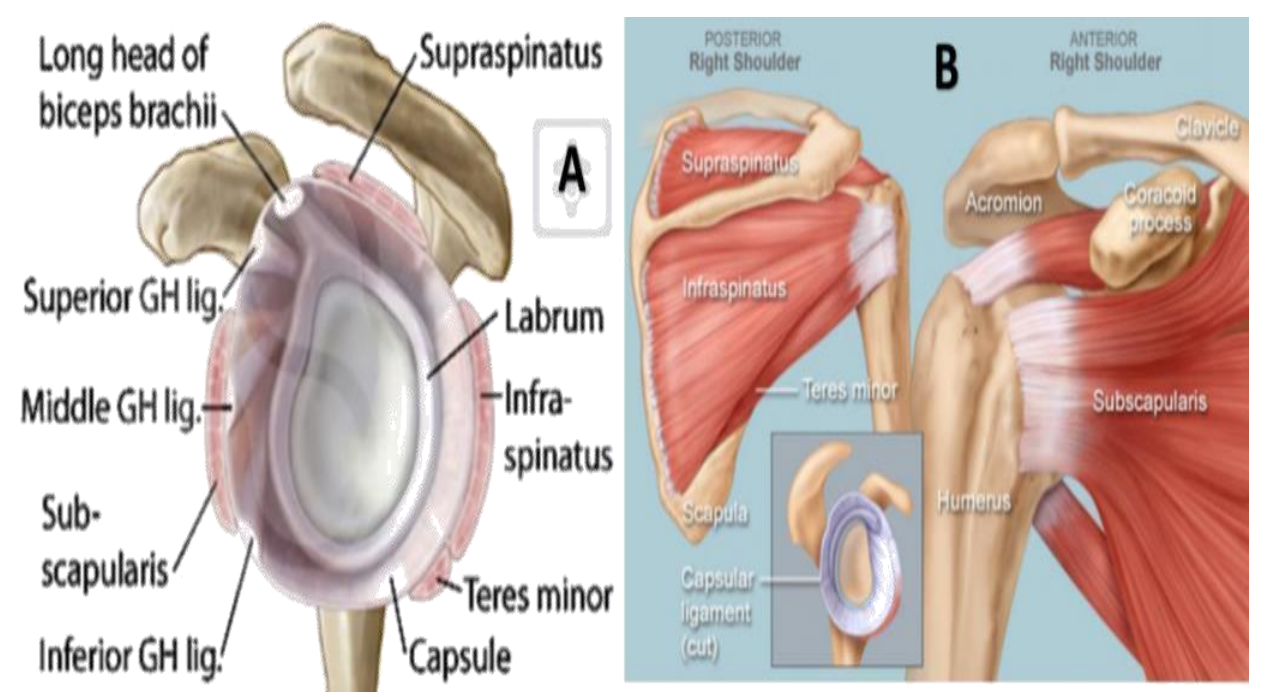

Figure1. (A): Glenohumeral ligaments and its relation to rotator cuff muscles; (B) Rotator Cuff Muscle, front and back view of shoulder girdle [8].

Shoulder dislocation in birth palsy can be induced by muscle imbalance, and to flattening of the humeral head [10]. Cross innervation results in co-contractions of the synergistic and antagonistic muscles[3], muscle co-contractions may occurs after both spontaneous and postoperative nerve regeneration in proximal brachial plexus lesions because aberrant nerval re- innervation at the site of lesion, or repair[11].Co-contraction between shoulder abductors and adductors will produce limitation of shoulder elevation and shoulder adduction contracture (or internal rotation) will develop. In co-contraction between elbow flexors and shoulder abductors, in elevated hand to mouth movement, the shoulder will be involuntarily elevated, as in blowing a trumpet (so called the "trumpet sign"), if severe cross-innervation present, the arm to body angle is less than 40 degrees, mild cross-innervation is present; if the angle is more than 80 degrees. In birth palsy with an internal rotation contracture of the shoulder; the (trumpet sign) is a necessary compensatory mechanism to reach one's mouth [2].

Elbow flexion leads to striking of the lower arm against the thorax, so the hand could not, or could with only simultaneous elevation of the shoulder, be brought up to the mouth [12]. The residual deformities in the brachial plexus palsy are classic and consist of discrepancy of bone growth in the affected side, the clavicle and the scapula, muscular imbalance around the shoulder region and co-contractions of antagonistic muscles. The combination of all the above mentioned residuals of brachial plexus palsy result in the upward and lateral fixation of the scapula [13]. The extension and elevation of the scapula above the clavicle is termed the 
SHEAR (scapular hypoplasia, elevation, and rotation) deformity, a functional and aesthetic deformity, it is the most obvious deformity and parents may seek surgical correction. Medial rotation contracture (MRC) is an internal rotation contracture produced by a constant downward pressure induced by the acromion on the humeral head. In a normal shoulder girdle at rest, the acromion does not articulate with the humeral head, in (MRC), one of the major bony deformities is the SHEAR deformity which is the cause of tilting of the acromioclavicular joint from a neutral position, which leads to displacing the humeral head from the glenoid fossa [13].

Birch's Classification System: Four stages of deformity are recognized: medial rotation contracture, posterior subluxation, posterior dislocation, and complex subluxationdislocation [14] with increasing severity as a result of a medial rotation deformity, Description as follows: coracoid overgrowth, restriction of passive lateral rotation by $30-40$ degrees so deformity medial rotation contracture. Passive lateral rotation is restricted to about 10 degrees, head of humerus is prominent to palpation and no secondary deformities of the acromion, the coracoid or the glenoid so deformity posterior subluxation (simple). The head of humerus can be seen and palpated behind the glenoid + fixed MRC fixed flexion pronation deformity of forearm so deformity posterior dislocation (simple). Diminished compensatory thoracoscapular movement, painful shoulder, and extremely poor shoulder function in complex subluxation the articulation is between the humeral head and the false glenoid so deformity complex subluxationdislocation [3].

Physical Examination: the most important clinical sign in the group of patients with medial rotation contracture with joint deformity and posterior subluxation or dislocation is the (scapular sign of Putti) which is the elevation of the upper corner of the scapula when the shoulder is passively adducted and externally rotated with the elbow in 90 degrees of flexion, produced by posterior subluxation and contracture of the upper fibers of the subscapularis muscle [15]. The clinical sign of shoulder dislocation is loss of external rotation [16]. Two specific measurements are noticed in patients with internal rotation deformity with posterior dislocation of the humeral head [17]. The inferior glenohumeral angle: In the normal shoulder, it is at least 150 degrees, in birth palsy, contracture of the inferior capsule, the latissimusdorsi and the teres major muscles is so tight that the active and passive angle is decreased to about 30-40 degrees. Weakness of the shoulder abductor muscles is assisted by substantial discrepancy between the passive and active ranges.
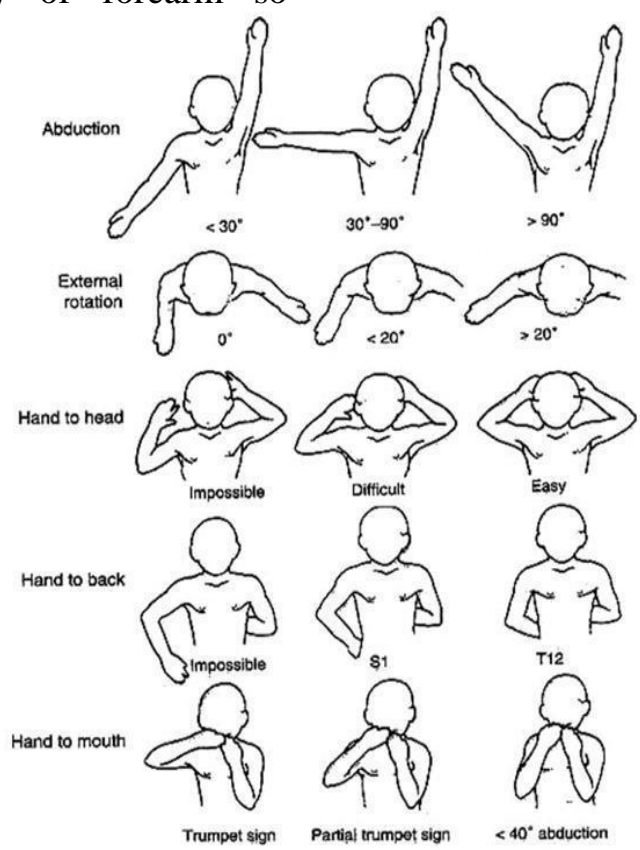

Value

$\|$

III

IV

Figure2. The Modified Mallet Classification for assessing upper trunk function in patients with brachial plexus birth palsy. Grade I represents no function, and Grade V represents normal function. Grades II, III, and IV are depicted for each category [18]. 
The posterior glenohumeral contracture: normal value is 70 degrees, whilst in sever contracture it may be decreased to 0 degree [17]. The scapular elevation is developed both by adductionexternal rotation (Putti's sign) and adductioninternal rotation (Zancolli's sign)[6].Pure abduction deformity is manifested by marked scapular elevation which is obtained by passive adduction of the humerus, severe functional disability may result due to the inability to adduct the arm[6]. The Modified Mallet scoring System (Fig. 2) [18]: will evaluate the upper limb with respect to five natural actions: global abduction of the arm, external rotation of the arm, bringing the hand behind the head, touching the hand to the back, and elevating the hand to the mouth [18].

\subsection{Radiological Assessment of Shoulder Sequelaein Birth Palsy}

For evaluation and classification of shoulder sequelae of birth palsy including plain X-Ray: both shoulders should be examined by anteroposterior and axial radiographs, to identify the changes on the affected side (Fig. 3) [20]; and CT, 3 D CT to assess the degree of glenoid version (Fig. 4), to identify dysplasia of the glenoid, and to determine the degree of subluxation of the humeral head and stages of SHEAR deformity [19]. The scapular deformity, SHEAR deformity is measured from the 3D reconstructions of the CT images (Fig. 5, 6).

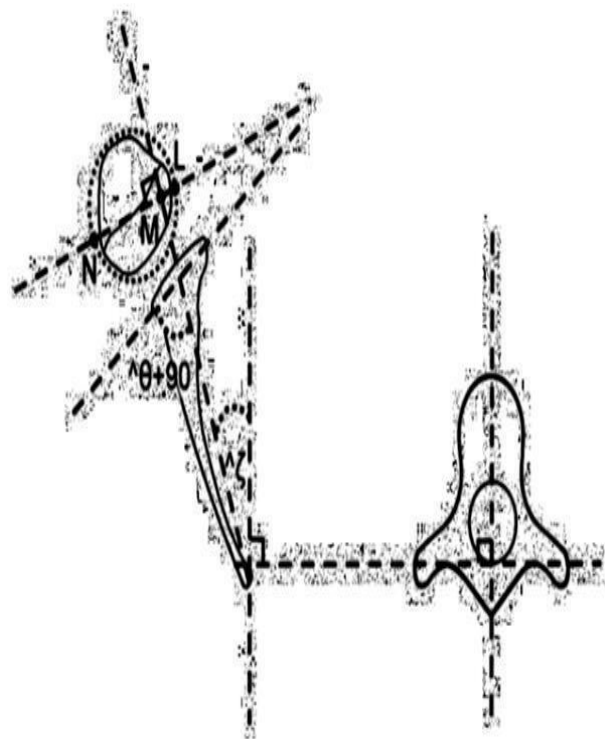

Figure3. The Method of Calculating Glenoscapular Angle: Schematic drawing showing the method of calculating Glenoscapular angle (glenoid version $\theta$ ), posterior subluxation of the humeral head and

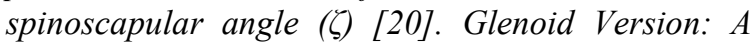
scapular line connecting the medial margin of the scapula to the middle of glenoid at the midglenoid level Gleno scapular Angle: Angle between scapular line and line on lateral surfer of glenoid interacting with humeral head. was measured and $\left(90^{\circ}\right)$ was subtracted form it to evaluate glenoid version value of $\left(^{\circ}\right)$ is considered normal but some variation from ( $14^{\circ}$ anteversion to $12^{\circ}$ )retro version is possible Humeral head subluxation :ratio greater diameter of humeral head divided by the perpendicular distance between the anterior portion of humeral head and scapular line and multiplied by 100 , a value of (50) is considered normal [20].

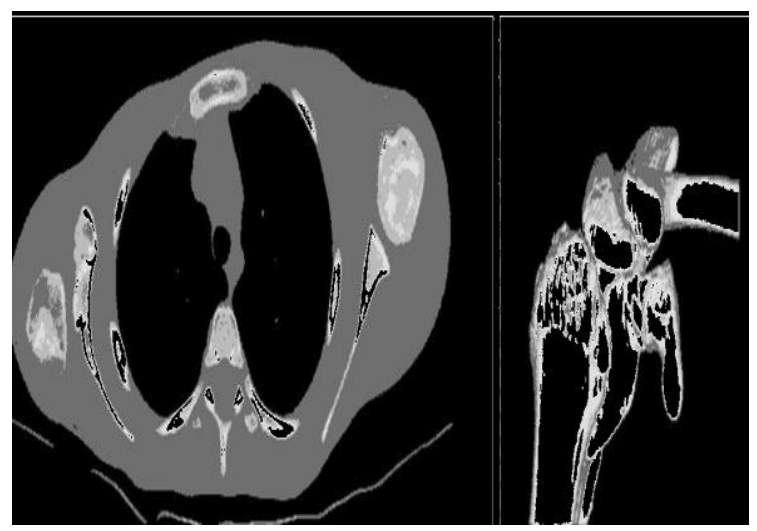

Figure4. Computerized Tomographic scan - and 3D CT using osseous margins as indicators showed shallow and flattened glenoid fossa, elevated and hypoplastic scapula, the coracoid process is directed inferiorly, and the acromion is abnormally tapered. The humeral head is poorly developed, hypoplastic and flattened. The clavicle may also be shortened and is laterally deformed. Posterior dislocation of the shoulder is a well- demonstrated sequela [21]. Using axial CT scans Waters et al. classified glenohumeral dysplasia according to the criteria demonstrated in Tables 1 and 2.

Table1. Assessment of deformity of gleno-humeral joint according to criteria of Waters et al [21].

\begin{tabular}{|l|l|}
\hline Classification & \multicolumn{1}{|c|}{ Description } \\
\hline $\begin{array}{l}\text { Type I, normal } \\
\text { Glenoid }\end{array}$ & $\begin{array}{l}\text { Less than 5 difference in retroversion } \\
\text { between affected and non-affected } \\
\text { glenoid }\end{array}$ \\
\hline $\begin{array}{l}\text { Type II, mild } \\
\text { deformity }\end{array}$ & $\begin{array}{l}\text { More than 5 difference in } \\
\text { retroversion between affected and } \\
\text { non-affected glenoid }\end{array}$ \\
\hline $\begin{array}{l}\text { Type III, } \\
\text { Moderate } \\
\text { deformity }\end{array}$ & $\begin{array}{l}\text { Posterior subluxation of humeral } \\
\text { head-less than 35\% of head is } \\
\text { anterior to the scapular line }\end{array}$ \\
\hline $\begin{array}{l}\text { Type IV, } \\
\text { Severe } \\
\text { deformity }\end{array}$ & $\begin{array}{l}\text { Presence of fasle Glenoid } \\
\text { Severe flattening of humeral head } \\
\text { and glenoid with progressive or } \\
\text { complete posterior dislocation }\end{array}$ \\
\hline Type V & $\begin{array}{l}\text { Posterior humeral head dislocation in } \\
\text { infancy }\end{array}$ \\
\hline Type VI & $\begin{array}{l}\text { Growth arrest of proximal aspect of } \\
\text { humerus }\end{array}$ \\
\hline Type VII
\end{tabular}


Table2. Preoperative modified Mallet score.

\begin{tabular}{|l|c|c|c|c|c|}
\hline \multicolumn{5}{|c|}{ Preoperative modified Mallet score } \\
\hline $\begin{array}{c}\text { Age } \\
\text { group } \\
\text { (yrs) }\end{array}$ & $\begin{array}{c}\text { Global } \\
\text { abduction }\end{array}$ & $\begin{array}{c}\text { Global } \\
\text { Ext. } \\
\text { rotation }\end{array}$ & $\begin{array}{c}\text { Hand to } \\
\text { neck }\end{array}$ & $\begin{array}{c}\text { Hand to } \\
\text { spine }\end{array}$ & $\begin{array}{c}\text { Hand to } \\
\text { mouth }\end{array}$ \\
\hline $\begin{array}{l}\text { first } \\
\text { group) } \\
<4\end{array}$ & $60-100$ & $-40-0$ & $\begin{array}{c}\text { Not } \\
\text { possible } \\
\text { to } \\
\text { difficult }\end{array}$ & $\begin{array}{c}\text { Not } \\
\text { possible } \\
\text { to level } \\
\text { of S1 }\end{array}$ & $\begin{array}{c}\text { Marked } \\
\text { to partial } \\
\text { trumpet }\end{array}$ \\
\hline $\begin{array}{l}\text { (secon } \\
\text { d } \\
\text { group) } \\
\geq 4\end{array}$ & $70-100$ & $-45-20$ & $\begin{array}{c}\text { Not } \\
\text { possible } \\
\text { to } \\
\text { difficult }\end{array}$ & $\begin{array}{c}\text { Not } \\
\text { possible } \\
\text { to } \\
\text { level of } \\
\text { S1 }\end{array}$ & $\begin{array}{c}\text { Marked } \\
\text { to partial } \\
\text { trumpet } \\
\text { sign }\end{array}$ \\
\hline
\end{tabular}
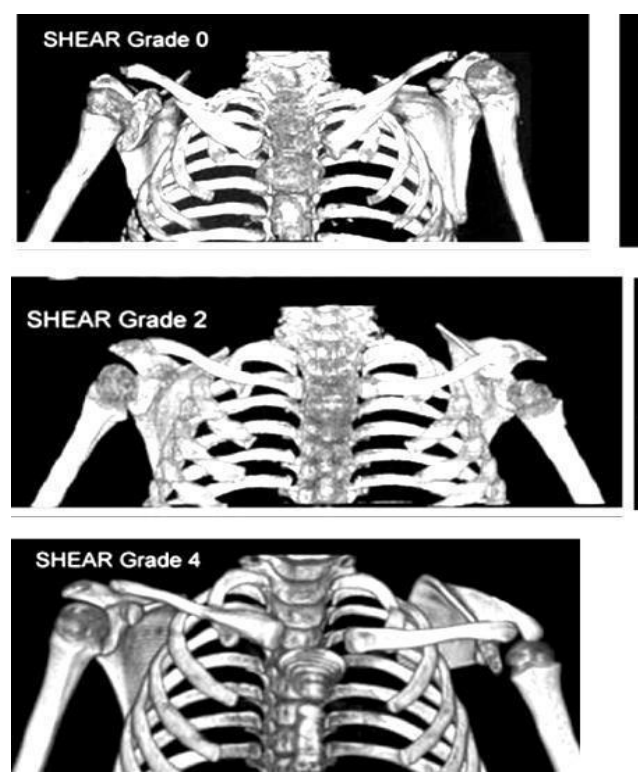

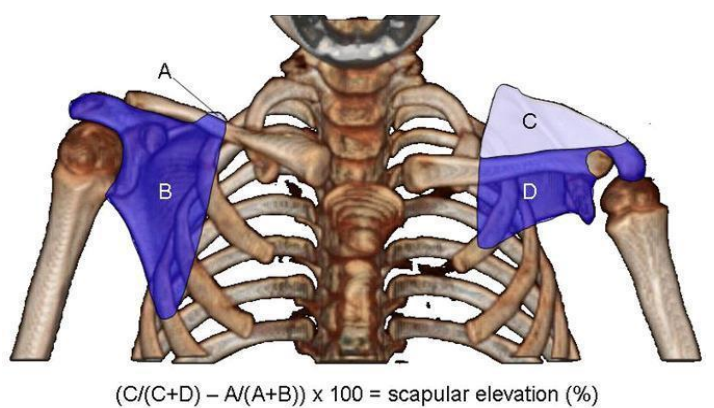

Figure5. Measuring the SHEAR deformity (Measuring scapular elevation to quantitate the extent of the SHEAR deformity) [22].
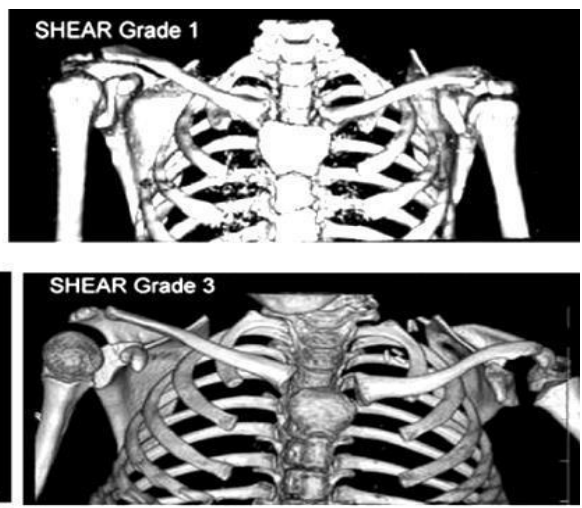

Figure6. Stages of the SHEAR deformity: The different SHEAR stages of scapular deformity as determined by three dimensional computer tomography. In SHEAR Grade 0: less than 2\% of the scapula, less than $20 \%$ of the superior border and less than $6.5 \%$ of the medial border are visible above the clavicle. In SHEAR Grade 1: 2$3.6 \%$ of the scapular area, 20-45\% of the superior border and 6.5-16.5\% of the medial border are visible over the clavicle. In SHEAR Grade 2: 3.6-20\% of the scapular area, 45-58\% of the superior border and 16.5-28\% of the medial border are visible above the clavicle. In SHEAR Grade 3: 20-45\% of the scapula, 58-68\% of the superior borderand 28-50\% of the medial border are visible over the scapula. In SHEAR Grade 4: more than $45 \%$ of the area of the scapula, more than $68.5 \%$ of the superior border and more than $50 \%$ of the medial border are visible over the scapula [20].

\subsection{Surgical Management of Secondary Shoulder Deformities in OBPI}

The Mod Quad Procedure improves shoulder abduction and flexion. Release of major internal rotator muscles: subscapularis, teres major, latissimusdorsi, pectoralis major and minor. Teres major and latissimusdorsi are transferred to the teres minor, increasing abduction, external rotation and scapular stability. Neurolysis and decompression of the axillary nerve further increase range of motion [21]. The triangle tilt surgery is a bony surgical procedure that detaches the distal acromioclavicular triangle ("ACT", with its sides defined by the clavicular shaft and the acromion process and an imaginary line connecting their medial ends its base)-humeral head complex from the abnormally positioned scapula; subsequent reversal of the anterior tilt of the ACT then would allow a natural rotation of the humeral head back into a more neutral position within the glenoid fossa. This procedure differs from more conventional approaches (axillary nerve decompressions, tendon transfers, and external rotation osteotomy of the humerus) in that it addresses and corrects the scapular hypoplasia, elevation and external rotation (SHEAR) deformity associated with typical OBPI cases [22]. 
Between 1997 and 2004 Nath et al. [23] performed the Mod Quad operation on 98 patients with obstetric brachial plexus injury and persistent internal rotation deformity. Between February and August 2005, Nath et al. [24] performed the triangle tilt procedure on 40 patients. Triangle Tilt (TT) surgery should be preceded by Mod Quad surgery in cases with weak abduction and doesn't increase abduction if done alone [24]. Triangle tilt is ideally developed for patients who have suffered a medial rotation contracture and scapular elevation; the surgery is significant in the presence of complete glenohumeral dislocations mild, moderate and severe neurological defects and as salvage for failed previous reconstructive surgeries [25]. The TT procedure is an effective treatment option for children and can be used for adolescents without modification. The repositioning of the humeral head into the glenoid fossa, in a more anatomic reduction which induce normal the humeral head and glenoid remodeling. Triangle tilt surgery is effective in the treatment of bony deformations that occur during childhood because it directly addresses it (Figure 7) [22].

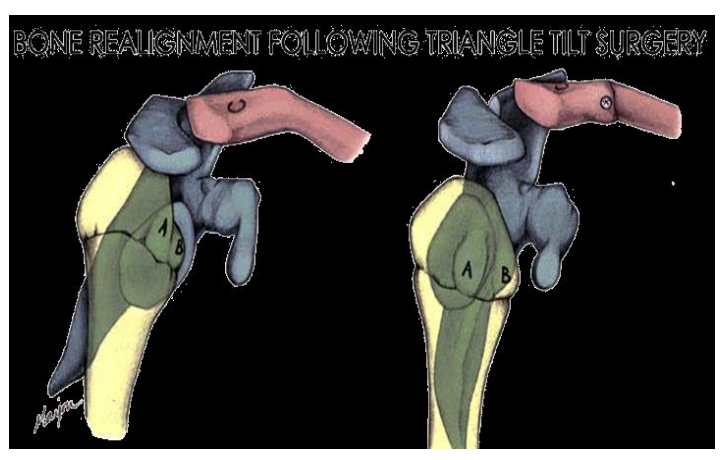

Figure7. Artist's rendering of acromioclavicular interface before (left); and after (right) triangle tilt surgery [13].

\section{PATIENT AND Methods}

Between 2013 and 2016, 34 patients suffering from obstetrical brachial plexus palsy (OBPP) with medial rotation contracture and defective shoulder abduction with posterior dislocation or subluxation of the humeral head and SHEAR deformity grade (2-4). Clinical evaluation : preoperative and postoperative depending their ability to do movement using a modified Mallet scale were scored on a scale of 1-5 with 1 being sever affected and 5 being normal the overall Mallet score ( 5-25) in based on 5 movement ( abduction, external rotation, hand to mouth , hand to neck and hand to spine). These patients were treated with one step shoulder soft tissue release (subscapularis and anterior soft tissues release) with or without tendon transfer (latissimusdorsi\&teres major to teres minor) and triangle tilt procedure and 13 patients were females and 21 were males. The age at surgery ranged from (3.4 years) to ( 9 years). According to age at surgery we divide cases into two groups : First group ( $<4$ years) number of cases ( 9 ) $(25 \%)$ ( range $3.4-4$ years ) mean age ( 3.6 years) and second group ( $\geq 4$ years) Number of cases ( 25 ) ( $73.5 \%$ ) ( range $4-9$ years ) mean age ( 6.1 years).

The right side was affected in 19 cases while the left side was affected in 15 cases, no bilateral affection was found in this study. 32 cases $(94.1 \%)$ had no previous surgery and were treated by physiotherapy. only 2 cases $(5.9 \%)$ had primary microsurgical repair of the plexus. Types of paralysis : complete ( OBPP) number of cases ( 12) ( $35.3 \%$ ) and partial ( OBPP) number of cases ( 22 ) ( $64.7 \%$ ).

All cases 34 were suffering from medial rotation contracture, 9 cases $(26.5 \%)$ were dislocated and 25 cases $(73.5 \%)$ were subluxated and (34) SHEAR deformity. The follow up duration ranged from (12 to 48 months) with mean of (31.2) months.

First group $<4$ years : 9 cases came with medial rotational deformity, abnormal contour (asymmetry) suspecting shoulder deformity subluxation or dislocation the head fullness in the posterior part of the shoulder that is created by the prominence of the humeral head by comparison with the uninvolved side. Short arm and SHEAR Scapula grade $(2-3)$.

Second group $\geq 4$ years: 25 cases came with medial rotational deformity, abnormal contour (asymmetry) suspecting shoulder subluxation or posterior dislocation, short limb is evident in all cases, with flexion deformity the elbow and the scapula is small, elevated, and rotated. SHEAR Scapula grade $2-4$ (Fig. 8); (Table 2).

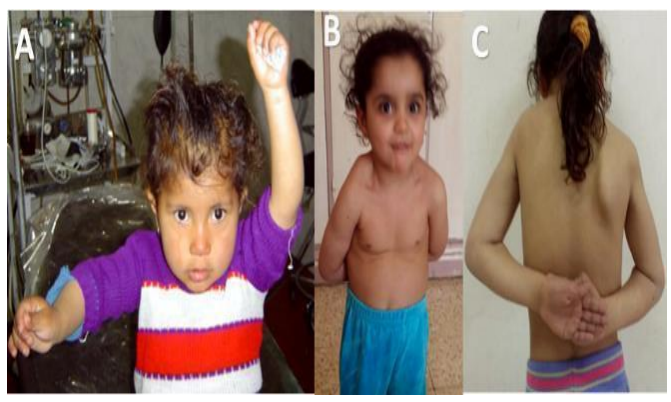

Figure8. (1) Shows external rotation and abduction insufficiency and (2 - 3) Show right scapula is small, winged and elevated in both photos. 
Degree of shoulder abduction and external rotation were recorded preoperatively. Test of the external rotation of the shoulder was done with shoulder adducted 90 degrees and elbow flexed 90 degrees indicate subscapularis is tight and test of the external rotation with abduction 90 o indicate pectoralis major is contracted.

Radiological preoperative ( $\mathrm{x}$ ray, CT and 3D CT ) for ( 34 ) cases ( percentage of humeral head anterior ( PHHA), glenoid version, scapular elevation and grade of SHEAR deformity ). Assess SHEAR deformity: referred as scapular elevation, the anterior view of the $3 \mathrm{D}$ reconstruction was used to measure the area over the clavicle through a universal desktop ruler and were recorded preoperative.

\section{Methods}

The operations were done to alleviate secondary deformities, to relocate the dislocated glenohumeral joint, enhance shoulder abduction and external rotation and to correct of SHEAR deformity arising from incomplete recovery following nonsurgical management or residual deformities following primary reconstruction.

(Shoulder soft tissue release):- In our study 34 cases $(100 \%)$ had performed anterior soft tissue release, release the subscapularis tendon near its insertion at the lesser tuberosity. In subluxation cases avoid injury of the anterior capsule to prevent anterior instability of the shoulder and decrease adhesion. In dislocation cases the capsule and the subscapularis tendon were blended with each other and the subscapularis tendon and the capsule were divided to the extent necessary to allow satisfactory reduction of the humeral head, now test the degree of external rotation in adduction and abduction, residual internal rotation deformity may be present due to contracture of pectoralis major tendon and /or conjoint tendon, doing z-plasty of the pectoralis major and /or release of the conjoint tendon.

The reduction was easily accomplished by external rotation of the arm. Posterior shoulder approach (Tendon transfer): with ( 60-900) shoulder abduction (adequate power of the deltoid) with weak ( $<200)$ external rotation either active or passive, ( 14 ) patient there is an indication for teres major and latissimusdorsi transfer to teres minor to improve abduction and external rotation and stabilize scapula . In our study, there are 14 cases $(41.2 \%)$ were subjected to tendon transfer, anterior shoulder release and triangle tilt procedure. The triangle tilt procedure began with an incision along the medial edge of the superomedial border of the scapula. Soft tissue was dissected from the scapula and the prominent superomedial angle of the scapula was excised with a bone cutter to create a rounded surface. An incision was made over the spine of the scapula and soft tissue dissection exposed the scapular spine, which was cut with an osteotome at base of acromion with scapular spine.

The scapula and the acromion process derotated after osteotomy, indicating preoperative twisting and internal rotation caused by the elevated scapula. Intraoperative $\mathrm{X}$ - ray was done with every osteotomy step to evaluate intraoperative reduction of shoulder joint and neutral tilt of ACT (Fig. 9). An incision was made over the distal third of the clavicle and the soft tissue was dissected to expose the clavicle. Osteotomy of the clavicle was performed lateral third and medial $2 / 3$ third with an osteotome and in contrast with the original procedure it was in step fashion and the distal and proximal clavicle segments were fastened together in semi rigid fixation with delayed absorbable sutures alone without using screws. The clavicle segments were noted to "twist" relative to each other after the osteotomy, indicating torsion in the clavicle due to scapular elevation. The bone removed during superomedial angle of scapular osteotomy was morcellizedand placed in the bone defect between the scapular spine and the acromion process and at clavicular osteotomy (Fig. 10).

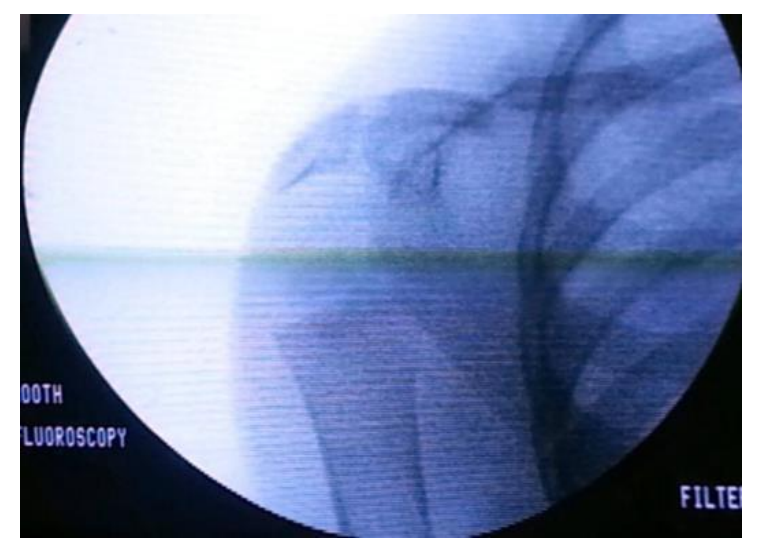

Figure9. Intraoperative C ARM X-ray. 


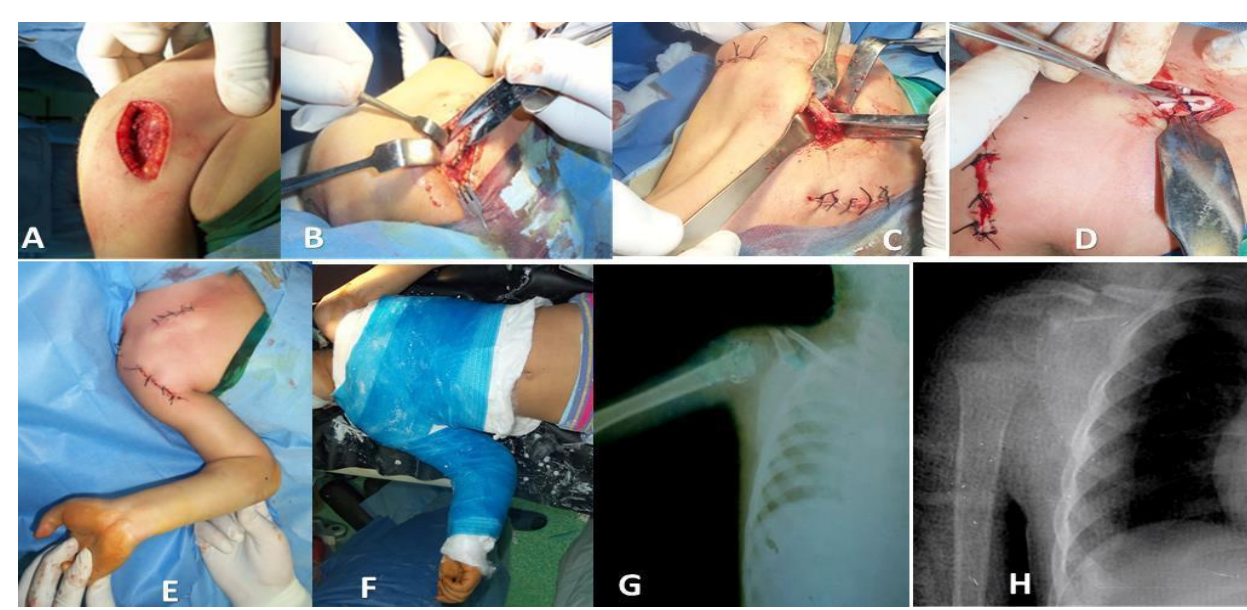

Figure10. Anterior capsule release and subscapularis tendon recession and Scapular osteotomy: A) Skin incision; B) tendon recession; C) Osteotomy of the base of the acromion , D) Clavicular osteotomy, Simi rigid fixation and grafting using morcellized bone from the scapular angle; E) closing the wound; F) postoperative cast

\section{Postoperative Care and Physio- THERAPY}

On table perform shoulder cast (30 degrees) adduction, (full) external rotation, and (full) forearm supination, is removed at 6 weeks. Early therapy target at this time is to increase AROM to shoulder flexion/abduction and elbow flexion. Abduction, external rotation fabricated brace is used as night splint for 3 months. At weeks 8 to 12 continue with progressive AROM activities. Constraint-induced therapy is recommended with attention paid to maintaining alignment. All compensatory movements to be discouraged such as hiking the hip, twisting or bending body backward. At weeks 12 we examine alignment of the scapula on the rib cage and alignment, strength and mobility of the gleno-humeral joint, strengthening of the scapular stabilizers to promote scapulo-humeral rhythm. Therapy protocol after our procedure generally begins with a frequency of twice weekly but should be modified on a case by case basis, physiotherapy is recommended for at least 6 months following our study. Pool therapy is recommended after 6 months in the rest follow up time.

\section{RESULTS}

The results of 34 cases are followed up for ranged from (12-48) months mean follow up (31.2) with continuous and intermittent physiotherapy. All cases showed improvement with different and variable degrees using modified Mallet scoring for assessment of their values.
First group <4years: 9 cases, mean age (3.6 year), mean follow up (30 months) with recovered plexuses. These cases showed improvements the medial rotational deformity; all cases with abnormal contour (asymmetry) of shoulder deformity (posterior dislocation of the head) become normal clinically, shortening was not clear in this group of patients, no bony prominence and scapula nearly of normal size, the mean improvement of shoulder abduction was (76.4) degrees, the mean improvement of shoulder external rotation was (70.1) degrees.

Second group ( $\geq 4$ years ) : 25 cases, mean age (6.1 years), mean follow up (31.3 months) showed improvement of the medial rotational deformity. Abnormal contour (asymmetry) of shoulder deformity (posterior dislocation) showed improvement clinically.

All cases with clinical shortening were clear to be improved in all cases in relation to normal side. Anteriorly, the coracoid process and clavicle start to remodel, posteriorly, the head was not palpated in cases of posterior dislocation, the scapula was improved in level and position, the acromion starts to remodel and improved bending. Preoperative Abd. Range (degrees) $<4$ years $(60-100)$ and Ext. rot. Range degree (-40-0), Preoperative Abd. Range (degrees) $<4$ years $(70-100)$ and Ext. rot. Range degree $(-45-20)$. Post-operative Abd. Range (degrees) $\geq 4$ years $(100-140)$ and Ext. rot. Range degree (60 - 90). Abd. Range (degrees) $\geq 4$ years $(100-150)$ and Ext. rot. Range degree (50-90) (Table 3). The mean improvement of shoulder abduction was (74.5) degrees, the 
One Step Shoulder Soft Tissues Reconstruction and Surgery Treatment of Triangle Tilt of Glenoid Due to Sequlae of Brachial Plexus BirthPalsy

mean improvement of shoulder external rotation was (69.4) degrees (Table 4). The relationship between the age at surgery (in years) and the improvement of shoulder abduction and external rotation (postoperative range- preoperative range). The older the age at surgery, the less the improvement in shoulder range of abduction and external rotation.

Table3. Preoperative and post-operative mean value of shoulder abduction and external rotation inFirst and second group groups.

\begin{tabular}{|c|c|c|c|c|c|c|c|c|}
\hline \multirow{2}{*}{$\begin{array}{c}\text { Age group } \\
\text { (years) }\end{array}$} & \multirow{2}{*}{$\begin{array}{c}\text { No. of } \\
\text { cases }\end{array}$} & $\begin{array}{c}\text { Percent } \\
(\%)\end{array}$ & $\begin{array}{c}\text { Abd. } \\
\text { Range } \\
\text { (degrees) }\end{array}$ & $\begin{array}{c}\text { Ext. rot. } \\
\text { Range } \\
\text { degree }\end{array}$ & $\begin{array}{c}\text { Preoperative } \\
\text { Range } \\
\text { (degrees) }\end{array}$ & $\begin{array}{c}\text { Abduction } \\
\text { improvement } \\
\text { (degrees) }\end{array}$ & $\begin{array}{c}\text { Mean } \\
\text { (degrees) }\end{array}$ & $\begin{array}{c}\text { Eange } \\
\text { improvement } \\
\text { (degrees) }\end{array}$ \\
\hline First group $<4$ & 9 & 26.5 & $60-100$ & $-40-0$ & $110-140$ & 76.4 & $60-90$ & 70.1 \\
\hline second group $\geq 4$ & 25 & 73.5 & $70-100$ & $-45-20$ & $100-150$ & 74.5 & $50-90$ & 69.4 \\
\hline
\end{tabular}

Table4. Preoperative and post-operative clinical outcomesof 9 cases of firstgroup $<4$ years.

\begin{tabular}{|l|c|c|c|c|}
\hline \multirow{2}{*}{\multicolumn{1}{c|}{$\begin{array}{c}\text { Age group } \\
\text { (years) }\end{array}$}} & \multicolumn{2}{c|}{ Preoperative } & \multicolumn{2}{c|}{ Postoperative } \\
\cline { 2 - 5 } & Abd. Mean & Ext. rot. Mean & Abd. Mean & Ext. rot. Mean \\
\hline First group $<4$ & 74.5 & -16.8 & 130 & 64.5 \\
\hline second group $\geq 4$ & 90.5 & -16.6 & 116.7 & 67.2 \\
\hline
\end{tabular}

Overall, the patients had improvement in their global shoulder function following shoulder soft tissue release and the tendon transfer and TT procedures, as measured by the aggregate scores of the modified Mallet classification (Tables $5 \& 6)$.

Table5. Preoperative and post-operative clinical outcomesof 25 cases of second group $\geq 4$ years.

\begin{tabular}{|c|c|c|c|c|c|c|}
\hline No & Pre-abd & Post-abd & Pre-ext & Post -ext & Pre totalMallet & Post total Mallet \\
\hline Mean & 84.4 & 130.5 & -12.7 & 82.2 & 11.7 & 19.8 \\
\hline SD & 15.1 & 6.3 & 12.5 & 10.9 & 1.2 & 2.2 \\
\hline P value & & $<0.001$ & & $<0.001$ & & $<0.001$ \\
\hline No & Pre- abd & Post-abd & Pre-ext & Post -ext & Pre total Mallet & Post totalMallet \\
\hline Mean & 87.6 & 116.8 & 1 & 72 & 11.1 & 19.7 \\
\hline SD & 10.9 & 11.4 & 20.1 & 14.1 & 1.4 & 2.1 \\
\hline P value & & $<0.001$ & & $<0.001$ & & $<0.001$ \\
\hline
\end{tabular}

Table6. Overall modified mallet score for (34 cases).

\begin{tabular}{|c|c|l|l|l|c|c|}
\hline $\begin{array}{c}\text { Overall } \\
\text { modified } \\
\text { mallet score }\end{array}$ & Range Preop & $\begin{array}{c}\text { Mean - SD } \\
\text { Preop }\end{array}$ & Range Postop & $\begin{array}{c}\text { Mean - SD } \\
\text { Postop }\end{array}$ & $\begin{array}{c}\text { Mean - SD } \\
\text { Difference }\end{array}$ & $\begin{array}{c}\text { Significant P } \\
\text { value }\end{array}$ \\
\hline & $7-14$ & $11.2(1.4)$ & $15-24$ & $19.7(1.9)$ & $8.5(0.4)$ & $<0.001$ \\
\hline
\end{tabular}

Table7. Pre-operative surgery mean modified mallet score was 11.2, this functional score greatly improved to $19.8(p<0.0001)$.

\begin{tabular}{|c|c|c|c|c|}
\hline Modified mallet score & Mean Pre & Mean Post & Difference & Significant p. value \\
\hline Abduction & 2.6 & 4.2 & 1.6 & $\mathrm{p}<0.0001$ \\
\hline External rotation & 2.4 & 3.8 & 1.4 & $\mathrm{p}<0.0001$ \\
\hline Hand to mouth & 2.7 & 4.2 & 1.5 & $\mathrm{p}<0.0001$ \\
\hline Hand to neck & 1.7 & 4.1 & 2.4 & $\mathrm{p}<0.0001$ \\
\hline Hand to spine & 1.8 & 3.4 & 1.6 & $\mathrm{p}<0.0001$ \\
\hline Overall Mallet score & 11.2 & 19.8 & 8.5 & $\mathrm{p}<0.0001$ \\
\hline
\end{tabular}




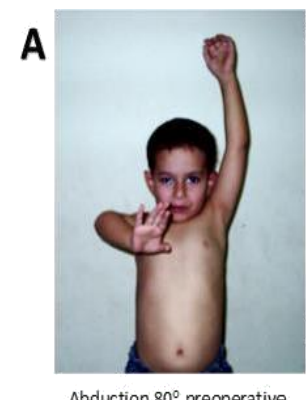

Abduction $80^{\circ}$ preoperative

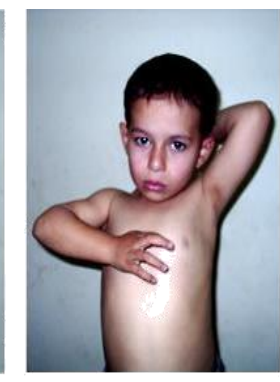

External rotation $-30^{\circ}$;

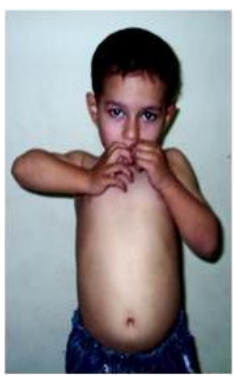

Marked trumpetsign

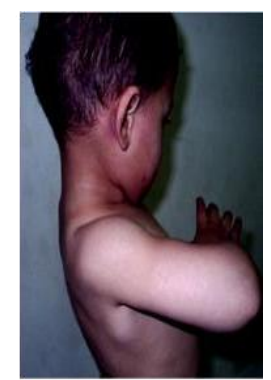

humeral head located posterioliv
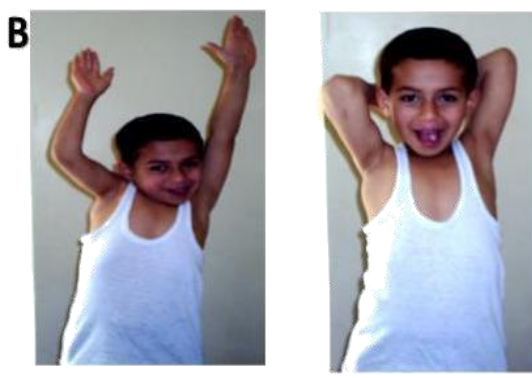

External rotation $90^{9}$ postop.

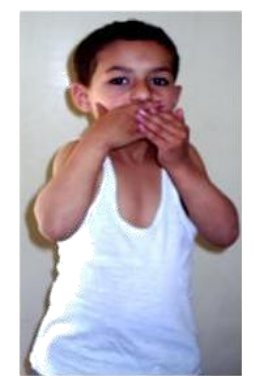

Trumpet sign (negative) postop

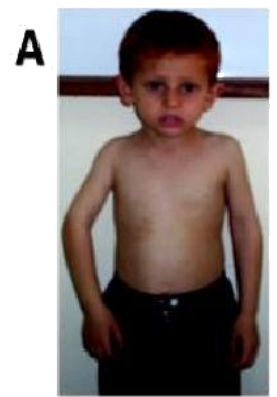

Preoperative during rest the patient show flextan of the ethow Iinternal metation of

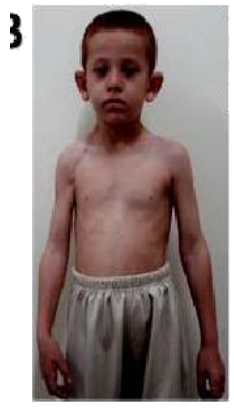

Postoperative rest position, Abduction $170^{*}$ postop absence of the deformity of the

right upper limb
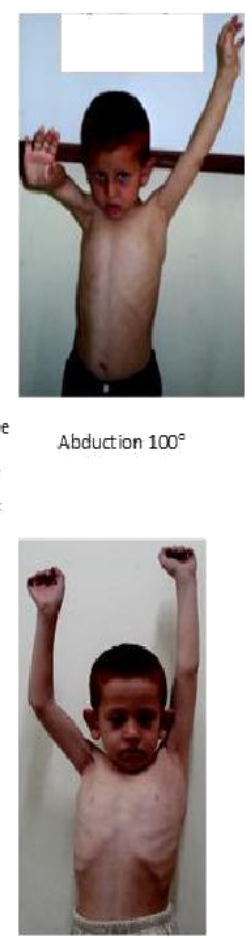

Abduction $100^{\circ}$

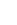

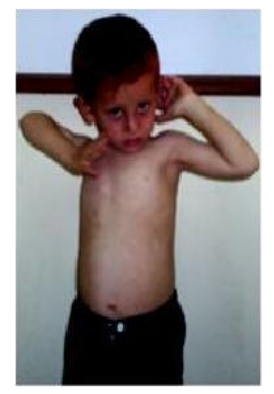

External rotation ( $30 \%$ )

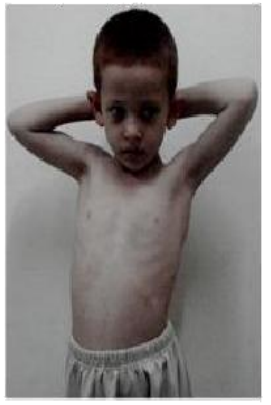

Extemal rotation show full function postap

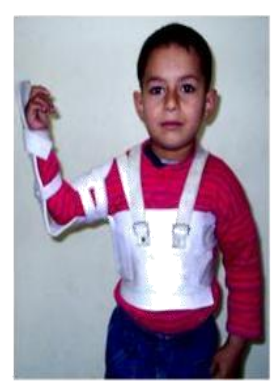

pt: with abd. Ext night splint.

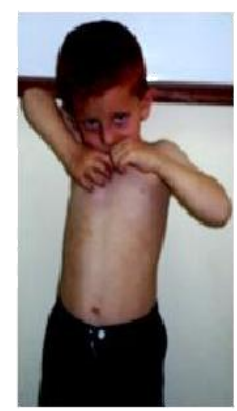

Hiand to mouth show marked trumpetisign

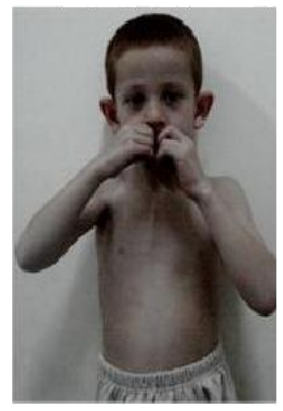

Hand to movth show hegative trumpet sign

postop:

Figure11. Male patient aged 3.5 years with Right OBPP, with internal rotation deformity, posterior dislocation and SHEAR deformity grade 3 with preoperative photos (A) and post-operative follow up photos 2 years duration $(B)$.

The mean aggregate Mallet score improved from (11.2) points (range 7 to 14 points) preoperatively to 19.7 points (range 15 to 24 points) postoperatively mean difference $(8.5) \mathrm{p}$ value 0.0001 (Table 7). Each element of the modified Mallet classification (global abduction improved from ( $2.6-4.2)$, global external rotation improved from ( $2.4-3.8$ ), hand-to-neck motion improved from ( $2.7-4.2$ ), hand-to-spine motion improved from ( $1.8-3.4)$ and hand-to-mouth motion improved from ( 1.7 4.1 ). No patient had deterioration in shoulder function as indicated by their ability to carry out the individual tasks or by the aggregate modified Mallet score (Figures 11\&12). 

Sequlae of Brachial Plexus BirthPalsy

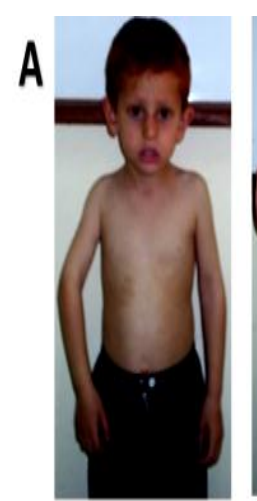

Preoperative during rest, the patient show flexion of the elhnw internal motation of

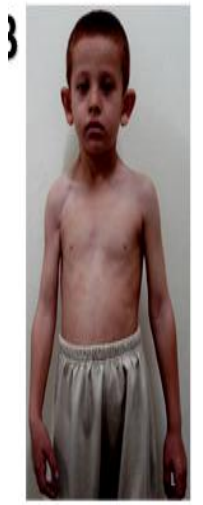

Postoperative rest position, Abduction $170^{\circ}$ postop. absence of the deformity of the

right upper limb

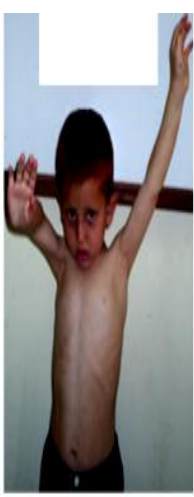

Abduction $100^{\circ}$

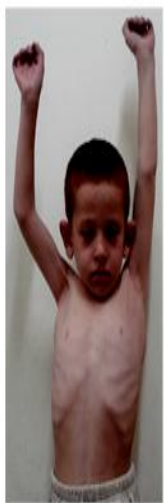

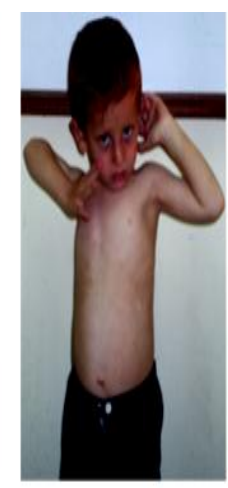

External rotation $\left(-30^{\circ}\right)$

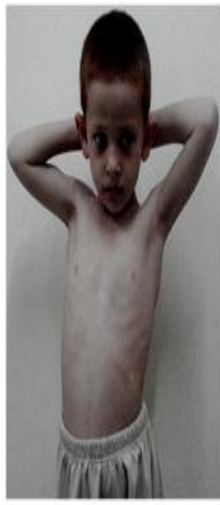

Extemal rotation show

fullfunction postop.

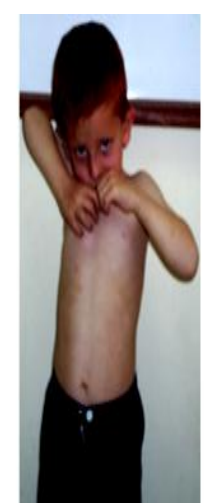

Hand to mouth show marked

trumpetsign

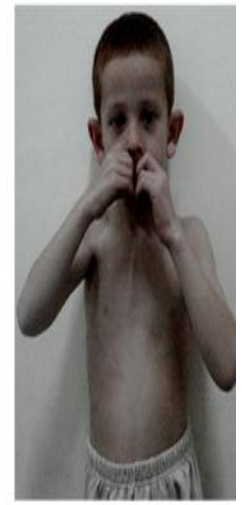

Hand to mouth show

negative trumpet sign

postop.

Figure12. Male patient aged 5 years with right OBPP with internal rotation deformity, posterior dislocation and SHEAR deformity grade 3 preoperative photos (on the (A) and postoperative follow up 2 years duration (B).

\subsection{Radiological Results}

Follow up ( X ray, CT and 3 D CT) of both shoulders was done in all patients of different age groups to detect union of clavicular and acromion osteotomy and measure glenoid version, percentage of the humeral head anterior (PHHA) and scapular elevation. The relationship between age at surgery and CT changes, show that the younger the age at surgery, the better is the degree of (PHHA), version of the glenoid and scapular elevation) (Figures 13-18).

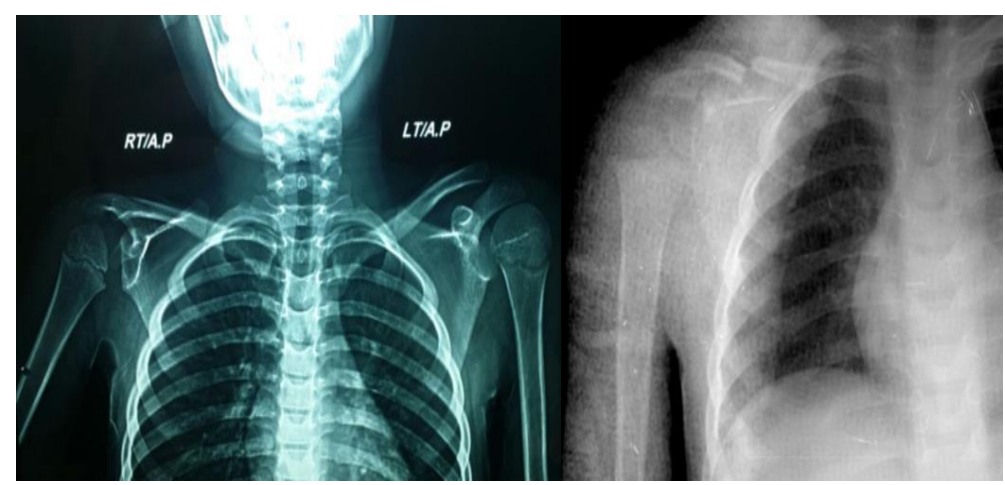

Figure13. (1) X ray of a child shows smaller more elevated scapula, elongation and beaking of the acromion and the coracoid process, Small and pearshaped proximal humeral epiphysis,Thinn metaphysis and diaphysis of the humerus, hypoplasia of the clavicle, small and shallow glenoid, (2 ) postoperative X ray shows scapular osteotomy, clavicle osteotomy, acromion osteotomy and shoulder joint relocation. 
One Step Shoulder Soft Tissues Reconstruction and Surgery Treatment of Triangle Tilt of Glenoid Due to Sequlae of Brachial Plexus BirthPalsy

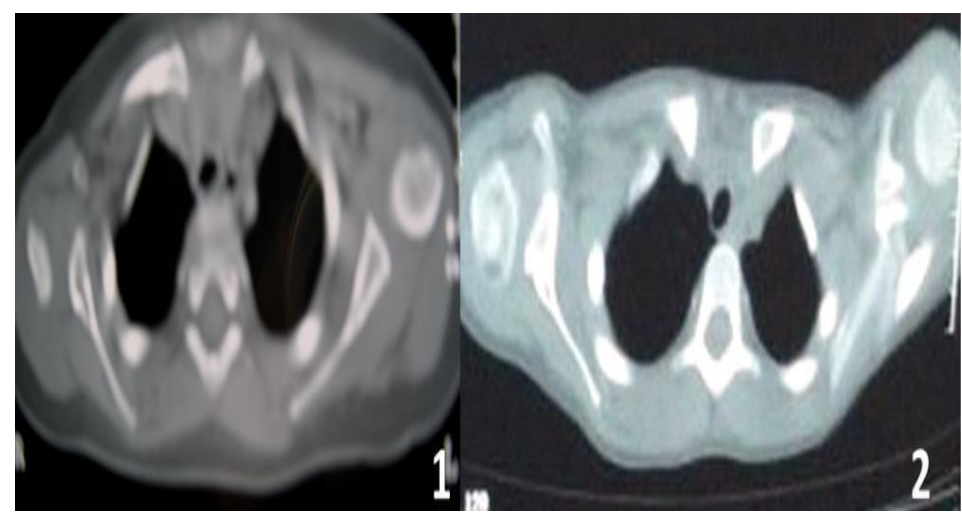

Figure14. (1) CT show the posterior dislocation of the right humeral head in a child aged 8 year, (2) postoperative CT show Postoperative Glenoid version 3degrees, Postoperative degree of ( PHHA ) $45 \%$.

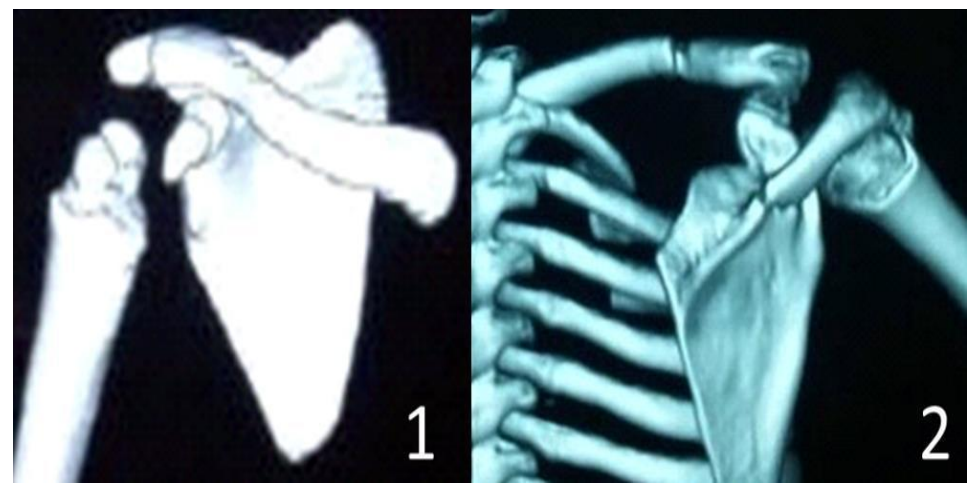

Figure15. Left Preoperative 3D reconstruction CT shows posterior dislocation, SHEAR deformity and 'right' postoperative showing improvement of SHEAR deformity scapular osteotomy, clavicle osteotomy, acromion osteotomy and shoulder joint relocation.
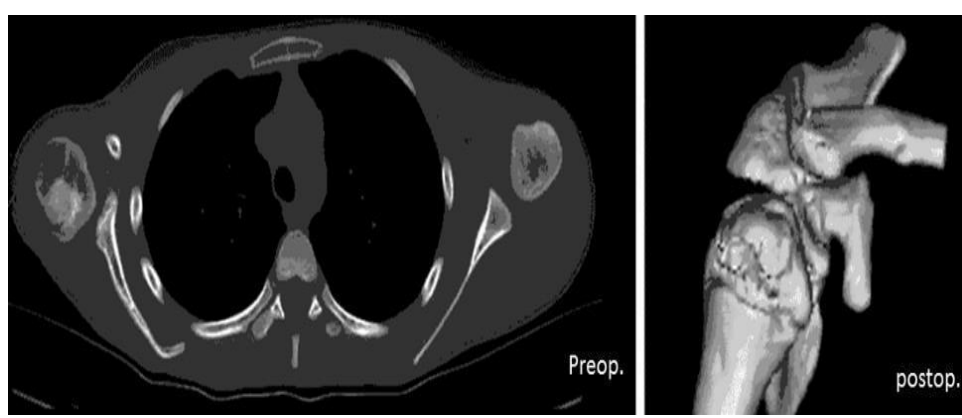

Figure16. Axial CT and three-dimensional CT views with 24 months postoperative showing relocation of the humeral head and improvement in glenoid version, PHHA, scapular elevation.

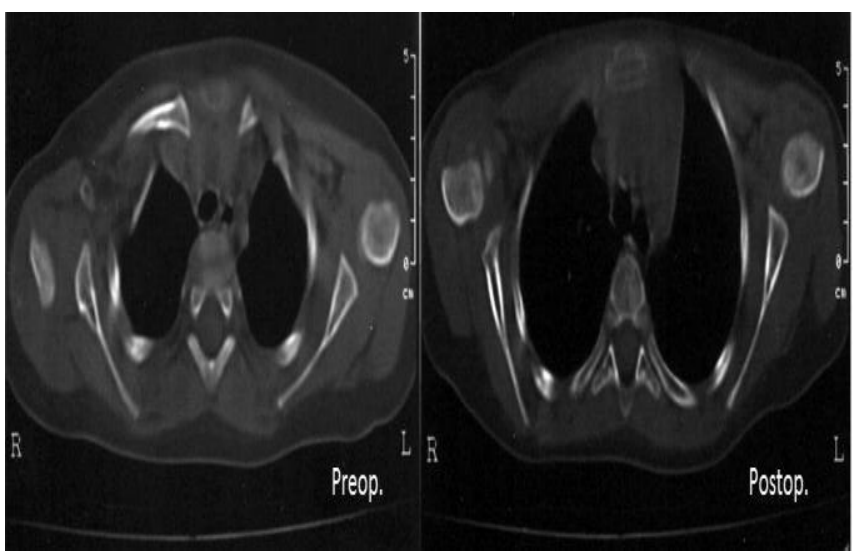

Figure17. Male patient 5 years old Right OBPP with posterior dislocation, Preoperative Glenoid retroversion50, Periooperative degree of (PHHA) 0\%, Postoperative Glenoid retroversion -9 degrees, Postoperative degree of ( PHHA ) $50 \%$. 


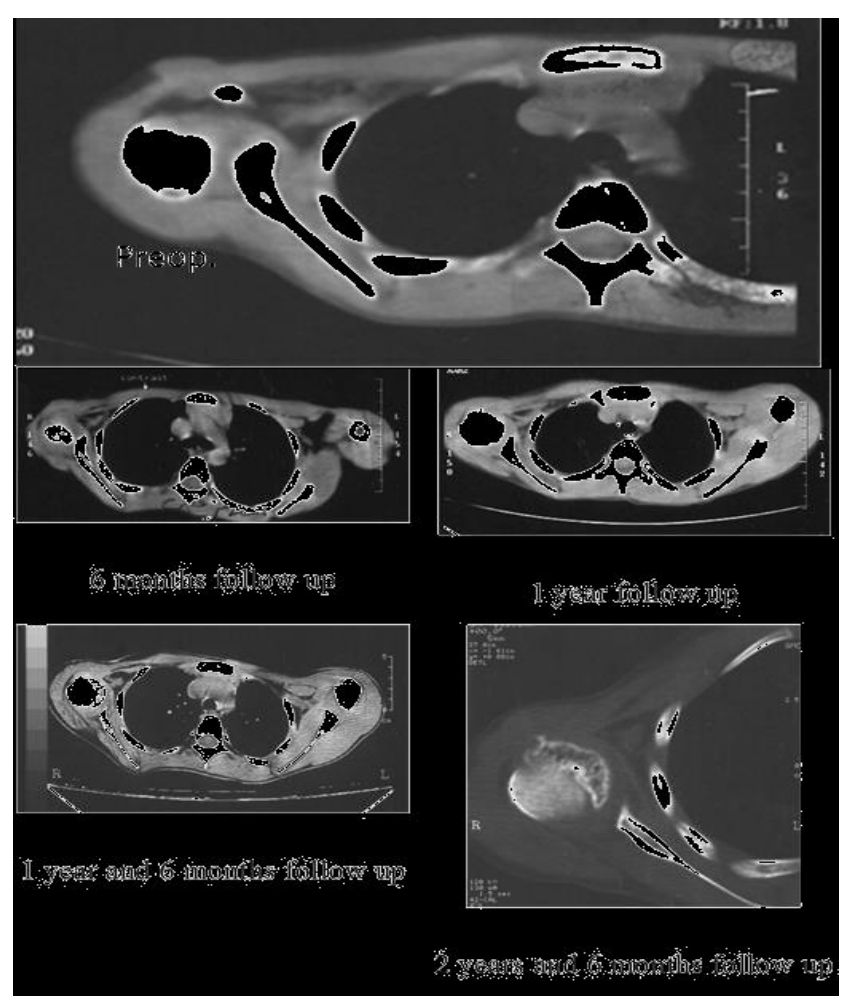

Figure18. A) Preoperative CT of right shoulder show posterior dislocation; B,C,D and E) Serial postoperative follow up CT scans.

The development of the glenohumeral joint was characterized by the amount of glenoid version and the degree of (PHHA) in relation to the axis of the scapular spine (Tables 8-10). Prior to soft tissue release the tendon transfer and TT surgery, the mean glenoid version of the affected shoulder was (17.2) (range, $-60^{\circ}$ to $-5^{\circ}$ ) and the mean (PHHA) was ( $8 \%$ ) (Range, $-15 \%$ to $30 \%$ ). At a mean of 31.2 months (range, 12 months to 48 months) following the tendon transfers, shoulder soft-tissue releases and TT procedure. The mean change (improvement) in glenoid version was $\left(-4.8^{\circ}\right)\left(\right.$ range $\left.-20^{\circ}-10^{\circ}\right), \mathrm{p}$ value 0.0001 and the mean improvement in (PHHA) was $(47.2 \%)$ (range $\left.30^{\circ}-60^{\circ}\right)$, p value 0.0001 , mean scapular elevation (7.4), (range 2-16).

Correlation between clinical and radiological results and age showed difference in abduction and scapular elevation were significantly correlated with age. For difference in abduction $(\mathrm{r}=0.4, \mathrm{p}=0.002)$ and scapular elevation $(\mathrm{r}=$ $0.4, \mathrm{p}=0.0045)$.

Table8. Preoperative and post-operative radiological outcomes of 9cases of first group < 4 years.

\begin{tabular}{|l|c|c|c|c|c|c|}
\hline \multicolumn{1}{|c|}{ No } & Pre PHHA & Post PHHA & $\begin{array}{c}\text { Pre } \\
\text { Version }\end{array}$ & Post Version & $\begin{array}{c}\text { Prescapular } \\
\text { elevation }\end{array}$ & $\begin{array}{c}\text { Post scapular } \\
\text { elevation }\end{array}$ \\
\hline Range & $-10-5$ & $40-60$ & $-20--5$ & $-10-10$ & $5-20$ & $2-15$ \\
\hline Mean & 9.4 & 48.1 & -10 & -1.4 & 12.7 & 7 \\
\hline Mean Difference & & 38 & & 8.5 & & -5.7 \\
\hline SD & 8.4 & 6.7 & 8.5 & 6.2 & 4.9 & 4.5 \\
\hline P value & & $<0.0001$ & & $=0.0026$ & & $=0.989$ \\
\hline
\end{tabular}

Table9. Pre-operative and post-operative radiological outcomesof 25 cases of second group $\geq 4$ years.

\begin{tabular}{|l|c|c|c|c|c|c|}
\hline \multicolumn{1}{|c|}{ No } & $\begin{array}{c}\text { Pre } \\
\text { PHHA }\end{array}$ & Post PHHA & $\begin{array}{c}\text { Pre } \\
\text { Version }\end{array}$ & $\begin{array}{c}\text { Post } \\
\text { Version }\end{array}$ & $\begin{array}{c}\text { Pre- } \\
\text { scapular } \\
\text { elevation }\end{array}$ & $\begin{array}{c}\text { Post scapular } \\
\text { elevation }\end{array}$ \\
\hline Range & $-15-30$ & $30-60$ & $-60--5$ & $-20-7$ & $5-48$ & $5-16$ \\
\hline Mean & 7.5 & 46.8 & -19.8 & -5.9 & 23.6 & 7.5 \\
\hline Mean Difference & & 39.3 & & 13.8 & & -16.2 \\
\hline SD & 15.3 & 8.8 & 16.1 & 6.9 & 12.8 & 3.5 \\
\hline P value & & $<0.0001$ & & $<0.0001$ & & $<0.0001$ \\
\hline
\end{tabular}


One Step Shoulder Soft Tissues Reconstruction and Surgery Treatment of Triangle Tilt of Glenoid Due to Sequlae of Brachial Plexus BirthPalsy

Table10. Preoperative and post-operative radiological outcomes of 34 cases (PHHA:percentage of humeral head anterior), glenoid version and scapular elevation.

\begin{tabular}{|l|c|c|c|c|c|c|}
\hline \multicolumn{1}{|c|}{ No } & Pre PHHA & Post PHHA & $\begin{array}{c}\text { Pre } \\
\text { Version }\end{array}$ & Post Version & $\begin{array}{c}\text { Prescapular } \\
\text { elevation }\end{array}$ & $\begin{array}{c}\text { Post scapular } \\
\text { elevation }\end{array}$ \\
\hline Range & $-15-30$ & $30-60$ & $-60--5$ & $-20-10$ & $5-48$ & $2-16$ \\
\hline Mean & 8 & 47.2 & -17.2 & -4.8 & 20.7 & 7.4 \\
\hline Mean Difference & & 39.14 & & 12.3 & 12.2 & -13.3 \\
\hline SD & 13.7 & 8.2 & 14.6 & 6.8 & & 3.7 \\
\hline P value & & $<0.0001$ & & $<0.0001$ & & $<.0001$ \\
\hline
\end{tabular}

\section{DISCUSSION}

The abduction deficit can be managed by shoulder soft tissue procedures including contracture releases, axillary nerve decompression and tendon transfers. While the SHEAR deformity is the cause of medial rotation contracture is more difficult to correct [25].External rotation osteotomy of the humerus does not correct the primary scapular elevation and rotation but improve the position of the hand and forearm and may help the resting position and active external rotation at the shoulder. Therefore, a bony surgical approach is indicated to correct the deformity, and conceived as a response to the abnormal bony development seen in the SHEAR deformity. The protracted scapula and the abnormal anterior rotation of the clavicle together causes the acromioclavicular plane to tilt forward and thereby lead to the impingement of the acromion upon the humeral head [22]. Triangle Tilt surgery is a more specific operation because it addresses the root cause of the medial rotation [20].

Kirkos et al. ( 1998 ) in brachial plexus birth palsy 22 cases means age 10 years follow up vary years the effect derotation osteotomy of the humerus on global shoulder function with no mean increase in shoulder abduction was $27 \mathrm{deg}$. (range 0-60 deg.), average increase external rotation was 250 (range 5-85 deg.) [26]. Al Qattan (2009) managed 17 patents of OBPI with limited shoulder abduction and external rotaion with mean age 6 years, by derotation osteotomy of the humerus, reexamined to the clinic at a mean of 10 years follow up found surprisingly a significant $(p=0.003)$ decrease in shoulder abduction on long term follow up (the mean shoulder abduction was 135 deg., 146 dg. and 109 deg., measured pre, early post, and late post-operative respectively) [27].
Wateres et al ( 2006 ) in brachial plexus birth palsy 27 cases the effect derotation osteotomy of the humerus on global shoulder function, means age 7.6 years follow up 3.7 years, Mallet score increased from 13 to $18(\mathrm{p}=0.0001)$ mean external rotation at achieved was osteotomy was 640 [28].

Poyhia et al ( 2011 ) in 13 cases with shoulder sequlae of OBPI relocation of the humeral head in glenoid with mean age ( 8.5 ) with follow up (3.8) years resulted in significant improvement in Mallet score $5.5(\mathrm{p}=0.003)$ [29].

Nath et al. ( 2010 ) managed 25 cases of complete OBPI resulted in limited shoulder function and examined the results of triangle that surgery on shoulder function and development all patents had undergone modified quad surgery prior to triangle. 25 cases with ( 0.75-12 ) years were followed up clinically for more than 2 years and results were a significant increase in the overall Mallet score from 12 to 14.6 ( 2.6 points, $\mathrm{p}<0.0001$ ) and improvement in shoulder function, glenoid version and humeral radiological improvement from $\mathrm{CT}$ and 3DCT reconstructions study posterior subluxation from $13 \%$ to $30.4 \%$ postoperative ( $\mathrm{p}<0.05)$ and glenoid version from $-28 \mathrm{deg}$. to 16.5 deg. $(\mathrm{p}<0.05)$ there war lesser elevation of the affected scapula from $6.4 \%$ to $2.9 \%$ ( p $<0.05$ ) the results showed effective ness of TT sugary bony surgical procedure and outcome in OBP [13].

Rahul k Nath and Chandra managed (2013) 22 children with medial rotation contracture and scapula deformity secondary to obstetric brachial plexus age ranging from ( $2.1-11.8$ years), functional movements were evaluated preoperative and 5 years follow up for triangle lilt surgery by modified mallet scale which improved from $14.1 . \pm 2.7$ to $20.3 . \pm 2.5$ [30]. . 
Rahul k Nath (2016), compare outcome of modified Quad and TT OBPP cases 10 aged 2 to 11- 8 years, male and 10 female to results of conventional operative procedure found that pre-revision surgery average modified Mallet score was $12 . \pm 1.5$. and the function score was greatly improved to $18 \mathrm{t} 2.3$ ( $\mathrm{p}<0.001$ ) and 16.3. $\pm 11(\mathrm{p}<0.0002)$ at least one year's follow up and preoperative PHHA, glenoid version and SHEAR were $14.6 \pm 21.7$, - 31.6 \pm 19.3 and $16.1 \quad \pm 14.7$ respectively, postoperative PHHA, glenoid version and SHEAR were $31.9 \pm 13.6,-31.6(\mathrm{p}<0.001)$ , $16.3 \pm 11(\mathrm{p}<0.0002)$ and $11.9 \pm 13.5$ respectively [31].

In our study (34) cases which suffer from medial rotation contracture with shoulder subluxation or dislocation and SHEAR deformity in one step we addressed anterior shoulder release, tendon transfer and TT surgery when our result compared to results of other studies. We found improvement in clinical and radiological results of one step to others procedure of Nath (Mod Quad and TT surgery ) and humeral osteotomy. Advantage of our study is no need to expose the cases to 2 operations so decrease the risk of anesthesia on the cases, and decrease operative time, it was 2 hour and half at the beginning of the study then reduced to only one hour when we become trained and accustomed for the technique and approach.

We used only ( absorbable ) suture for fixation of clavicular osteotomy without screws so no metal was used in the procedure and make more liability to move the lateral segment and twist the clavicle without loss of bone contact and no cases of non-united clavicular osteotomy and no need for extraction of screws results of shoulder abduction showed significant increase as result of relocation of glenohumeral joint to neutral position and indirect decompression of axillary nerve as anterior shoulder release reduce posterior head subluxation and dislocation and TT procedure make the humeral head in its stable normal true anterior glenoid fossa by tilting the ACT so the humeral head relieved its compression on the axillary nerve so deltoid muscle function in normal pattern.

Each element of the modified Mallet classification (global abduction improved from
(2.6 - 4.2), global external rotation improved from $(2.4-3.8)$, hand-to-neck motion improved from (2.7-4.2), hand-to-spine motion improved from $(1.8$ - 3.4) and hand-to-mouth motion improved from (1.7- 4.1). No patient had deterioration in shoulder function as indicated by their ability to carry out the individual tasks or by the aggregate modified Mallet score. All patients regardless of their age (3.4 - 9) showed improvement in all shoulder function, the overall Mallet scores between younger $(<4$ years, $n=9)$ and older ( $\geq 4$ years, $n=25$ ) patients with both groups was improved after surgery and difference in abduction and scapular elevation were significantly correlated with age.

\section{CONCLUSION}

Statistically significant improvement in shoulder function and radiological outcomes after our study. Muscle releases and tendon transfers may arrest progressive glenohumeral dysplasia and possibly influence some of the long-term effects of joint malalignment and muscle imbalance in younger patients. Humeral osteotomy sometimes provides functional improvements however, it only moderately improves medial rotation contractures in mild to moderate cases and does not improve severe cases, and humeral osteotomy does not address the glenohumeral deformity, which is the major cause of loss shoulder functions in OBPP. The results of triangle tilt improves upper limb function especially shoulder external, hand to mouth and neck so in our study we combined in one step shoulder soft tissues reconstruction and triangle tilt procedure so improvement of shoulder function and development.

\section{REFERENCES}

[1] Hoeksma AF, TerSteeg AM, Dijkstra P. Shoulder contracture and osseous deformity in obstetrical brachial plexus injuries. J Bone Joint Surg Am 2003; 85-A (2):316-22.

[2] Van der Sluijs JA, Van Ouwerkerk WJR, de Gast A. Treatment of internal rotation contracture of the shoulder in obstetric brachial plexus lesions by subscapular tendon lengthening and open reduction: early results and complications. J PediatrOrthop B 2004; 13(3):218-24.

[3] Chuang DC, Ma HS, Wei FC. A new strategy of muscle transposition for treatment of shoulder deformity caused by obstetric brachial 
plexus palsy. PlastReconstrSurg 1998; 101(3):686-94.

[4] Gilbert A, Brockman R, Carlioz H. Surgical treatment of brachial plexus birth palsy. ClinOrthopRelat Res 1991; (264):39-47.

[5] Pearl ML. Shoulder problems in children with brachial plexus birth palsy: evaluation and management. J Am AcadOrthopSurg 2009; 17(4):242-54.

[6] Zancolli EA, Zancolli ER III. Reconstructive Surgery in Brachial Plexus Sequelae. In: Gupta A, Kay SPJ, Scheker LR (eds). The Growing Hand (Diagnosis and Management of the Upper Extremity in Children). London: Mosby. 2000; 805-823.

[7] Kon DS, Darakjian AB, Pearl ML. Glenohumeral Deformity in Children with Internal Rotation Contractures Secondary to Brachial Plexus Birth Palsy: Intraoperative Arthro graphic Classification. Radiology 2004; 231(3):791-5.

[8] O’Brien S, Taylor S, Ramkumar PN. Developmental Anatomy of the Shoulder and Anatomy of the Glenohumeral Joint In: Rockwood CA, Masten FA III (eds). The Shoulder. Philadelphia: W.B. Saunders. 1998; 1-33

[9] Jobe C. Gross Anatomy of the Shoulder. In: Rockwood C., Masten FI, editors. The shoulder. Philadelphia: W.B. Saunders.; 1998; P: 34-97.

[10] Dunkerton MC. Posterior dislocation of the shoulder associated with obstetric brachial plexus palsy. J Bone Joint Surg Br 1989; 71(5):764-6.

[11] Hierner R, Berger A. Treatment of cocontraction. In: Gilbert A (ed). Brachial Plexus Injuries. CRC Press; 2001; P: 303-11.

[12] Rühmann O, Gossé F, Schmolke S. Osteotomy of the humerus to improve external rotation in nine patients with brachial plexus palsy. Scand J PlastReconstrSurg hand Surg 2002; 36(6):349-55.

[13] Rahul K. Nath, Karicherla P, Mahmooduddin F. Shoulder function and anatomy in complete obstetric brachial plexus palsy: Long-term improvement after triangle tilt surgery.Child's NervSyst 2010; 26 (8):1009-19.

[14] Chuang DC, Ma HS, Wei FC. A new evaluation system to predict the sequelae of late obstetric brachial plexus palsy. PlastReconstrSurg 1998; 101(3):673-85.

[15] Zancolli EA. Classification and management of the shoulder in birth palsy. OrthopClin North Am 1981; 12(2):433-57.

[16] Moukoko D, Ezaki M, Wilkes D. Posterior shoulder dislocation in infants with neonatal brachial plexus palsy. J Bone Joint Surg Am 2004; 86-A (4):787-93.

[17] Birch R. Medial rotation contracture and posterior dislocation of the shoulder. In: Gilbert A (ed). Brachial Plexus Injuries. CRC Press; 2001; P: 249-59.

[18] Bae DS, Waters PM, Zurakowski D. Reliability of three classification systems measuring active motion in brachial plexus birth palsy. J Bone Joint Surg Am 2003; 85-A (9):1733-8.

[19] Friedman RJ, Hawthorne KB, Genez BM.: The use of computerized tomography in the measurement of glenoid version. J Bone Joint Surg Am 1992; 74 (7):1032-7.

[20] Rahul K. Nath, Paizi M.: Scapular deformity in obstetric brachial plexus palsy: A new finding. SurgRadiolAnat 2007; 29(2):133-40.

[21] Waters PM, Smith GR, Jaramillo D. Glenohumeral deformity secondary to brachial plexus birth palsy. J Bone Joint Surg Am 1998; 80(5):668-77.

[22] Rahul K. Nath, Humphries AD. Computed tomography of the shoulders in patients with obstetric brachial plexus injuries: a retrospective study. Ann SurgInnov Res 2008; 22(3):4-6.

[23] Rahul K. Nath. : Erb's palsy: the Nath method of diagnosis and treatment in: Nath RK (ed.) Obstetric Brachial Plexus Injuries. College station, TX: Virtual Book Worm 2007; 123-89.

[24] Rahul K. Nath, Liu X, Melcher SE, Fan J. Long-term outcomes of triangle tilt surgery for obstetric brachial plexus injury. PediatrSurgInt 2010; 26(4):393-9.

[25] Rahul K. Nath, Lyons AB, Melcher SE. Surgical correction of the medial rotation contracture in obstetric brachial plexus palsy. $\mathbf{J}$ Bone Joint Surg Br 2007; 89(12):1638-44.

[26] Waters PM, Bae DS. Effect of Tendon Transfers and Extra-Articular Soft-Tissue Balancing on Glenohumeral Development in Brachial Plexus Birth Palsy. J Bone Joint Surg 2005; 87(2):320-25.

[27] Kirkos JM, Papadopoulos IA. Late treatment of brachial plexus palsy secondary to birth injuries: rotational osteotomy of the proximal part of the humerus. J Bone Joint Surg Am 1998; 80(10):1477-83.

[28] Al-Qattan MM, Al-Husainan H, Al-Otaibi A. Long-Term Results of Low Rotation Humeral Osteotomy in Children with Erb's Obstetric Brachial Plexus Palsy. J Hand Surg European Vol 2009; 34(4):486-92.

[29] Waters PM, Bae DS. The effect of derotational humeral osteotomy on global shoulder function in brachial plexus birth palsy. J Bone Joint Surg Am 2006; 88(5):1035-42. 
One Step Shoulder Soft Tissues Reconstruction and Surgery Treatment of Triangle Tilt of Glenoid Due to Sequlae of Brachial Plexus BirthPalsy

[30] Pöyhiä T, Lamminen A, Peltonen J, et al. Treatment of shoulder sequelae in brachial plexus birth injury. ActaOrthop 2011; 82(4):482-8.

[31] Rahul K. Nath and Chandroma. Extended long term ( 5 years) outcomes of triangle tilt surgery in Obstetric Brachial Plexus Palsy, the open orthopedics journal, 2013; 7; P: 94 - 98.

[32] Rahul K. Nath and Chandroma. Improvement after mod Quad and triangle tilt revision surgical procedures in Obstetric Brachial Plexus Palsy, world journal orthopedics, 2016 November 18 , 7, (11) $752-757$.

Citation: Mohamed Abdelaziz MA Ghieth, Sayed El-Etewy Saoudy. One Step Shoulder Soft Tissues Reconstruction and Surgery Treatment of Triangle Tilt of Glenoid Due to Sequlae of Brachial Plexus Birth Palsy. ARC Journal of Orthopedics. 2017;2(1):7-17. doi:dx.doi.org/10.20431/2456-0588.0201002.

Copyright: (C) 2017 Authors. This is an open-access article distributed under the terms of the Creative Commons Attribution License, which permits unrestricted use, distribution, and reproduction in any medium, provided the original author and source are credited. 